\title{
Application of a Mixed Methods Approach to Identify Community-Level Solutions to Decrease Racial Disparities in Infant Mortality
}

\author{
Laurin J. Kasehagen • Kathleen Brandert • Brenda Nickol • Maureen Gatere • \\ Piia Hanson • Jane Bambace • Rita Beam • Shin Margaret Chao • Cheryl L. Clark • \\ Carrie Y. Hepburn • Maria A. L. Jocson • Millie Jones • Patricia McManus
}

Received: 27 August 2013 /Revised: 9 December 2013 / Accepted: 2 January 2014 /Published online: 11 February 2014

(C) Cobb/NMA Health Institute (outside the USA) 2014

\begin{abstract}
Objectives This study aimed to identify community-level actions to decrease racial disparities in infant mortality (IM). Design Six urban multidisciplinary teams generated ideas for decreasing racial disparities in IM using a mixed methods concept mapping approach. Participants rated each idea as to its necessity and action potential and grouped ideas by theme. A cluster analysis produced a series of visual representations, showing relationships between the identified actions and the clustering of actions into themes. Multidimensional scaling techniques were used to produce analyses describing the
\end{abstract}

\section{J. Kasehagen $(\bowtie)$}

MCH Epidemiology Program, Field Support Branch, Division of Reproductive Health, National Center for Chronic Disease Prevention \& Health Promotion, Centers for Disease Control and Prevention, 4770 Buford Hwy, NE, MS F74, Chamblee,

GA 30341, USA

e-mail: 1kasehagen@cdc.gov

L. J. Kasehagen $\cdot$ M. Gatere

CityMatCH, University of Nebraska Medical Center, 982170

Nebraska Medical Center, Omaha, NE 68198-2170, USA

K. Brandert • B. Nickol

College of Public Health, University of Nebraska Medical Center, 984355 Nebraska Medical Center, Omaha, NE 68198-4355, USA

P. Hanson

Association of Maternal \& Child Health Programs, 2030 M Street NW, Suite 350, Washington, DC 20036, USA

\section{J. Bambace}

Pinellas County Health Department, 205 Dr. Martin Luther King Jr. Street North, St. Petersburg, FL 33701, USA

R. Beam

Tri-County Health Department, 4857 S. Broadway St., Englewood, CO 80113, USA necessity of and action potential for implementing the proposed ideas. Participants identified actions communities could take to decrease racial disparities in IM and suggested applications of the knowledge gained from the mapping process. Results Participants produced a total of 128 actions, within 11 thematic clusters, for decreasing racial disparities in IM. The thematic clusters contained a range of elements designed to promote knowledge and understanding of the relationship between health and racism; improve educational systems and community opportunities; facilitate community-driven health promotion, marketing, and research; improve health services

\section{S. M. Chao}

Los Angeles Department of Public Health, 600 S. Commonwealth Ave. \#800, Los Angeles, CA 90005, USA

\section{L. Clark}

MCH Practice \& Analysis Unit, Division of Community Health Promotion, Florida Department of Health, 4052 Bald Cypress Way, Bin A-13, Tallahassee, FL 32399-1723, USA

\section{Y. Hepburn}

Tampa Bay Healthcare Collaborative, P.O. Box 2252, Dunedin, FL 34697-2252, USA

M. A. L. Jocson

Maternal, Child and Adolescent Health Division, California Department of Public Health, 1615 Capitol Avenue, MS 8306, P.O. Box 997420, Sacramento, CA 95899-7420, USA

\section{Jones}

Wisconsin Division of Public Health, 1 West Wilson, Rm 351, Madison, WI 53703, USA

\section{P. McManus}

Black Health Coalition of Wisconsin, Inc., 3020 West Vliet, Milwaukee, WI 53208-2461, USA 
for women; address physical and social environments that impact community health; prioritize resource allocation of community-based services; institutionalize strategies that promote equity across all systems; and create and support legislation and policies that address social determinants of health. Correlation coefficients of the clusters ranged from 0.17 to 0.90 . Average necessity ratings ranged from 2.17 to 3.73 ; average action potential ratings ranged from 1.64 to 3.61.

Conclusion Findings suggest that thematic clusters with high action potential usually represented ongoing community activities or actions communities could easily initiate. Community size, existing programs, partnerships, policies, and influential advocates were among the factors cited affecting feasibility of implementation. Clusters with lower action potential require broader, longer term, policy, institutional or systemwide changes, and significant resources. High necessity clusters often contained actions perceived as essential for change, but sometimes outside of a community's control. Participants identified a number of practical actions that were considered to hold potential for individual, community, and institutional changes which could result in decreasing racial disparities in IM.

Keywords Infant mortality $\cdot$ Racial disparities $\cdot$ Racism · Community $\cdot$ Concept mapping $\cdot$ Mixed methods

\section{Introduction}

The relationship between racism and discrimination (i.e., social constructs of attitudes, beliefs, behaviors, and practices of individuals or institutions which systematically prescribe and attempt to legitimize the subordination of a group of people by claiming that that group is biogenetically or culturally inferior) and adverse health outcomes has been well described [1-8]. While the direct and indirect effects of racism and discrimination on health have been difficult to establish and prove [4, $9,10]$, there is growing consensus among researchers that the health effects of racism and race-related exposures are cumulative [11-15]. In addition to the cumulative effects on individuals and subpopulations, racism and race-related exposures likely contribute to persistent disparities in birth outcomes over generations [14-18].

Communities have used participatory research methods and community models to explore and address disparities relating to public health policies, environment, neighborhood, transportation, housing, access to goods and services, physical activity, and a myriad of physical and mental health conditions [19-23]. Rarely, however, has the focus of communityinformed disparity work been to address the nexus of racial disparities and infant mortality [24, 25]. Community-informed solutions to racial disparities and infant mortality are necessary because, despite the significance of the adverse outcome (i.e., infant mortality and persistent racial disparities in birth outcomes) $[16-18,26,27]$ and the persistent conditions that contribute to poor outcomes $[4,5,11,28-31]$, much of the literature is problem focused. Medical treatment and prevention strategies tend to be narrowly focused, failing to take into account the complex nature of racism [32-35]. Byrd et al., for example, concluded that improving both prenatal care and maternal education attainment in Wisconsin would decrease infant mortality rates; however, these strategies would be unlikely to eliminate the black-white disparity in infant mortality and had the potential to widen the black-white gap [36]. Interventions, as described in Byrd, may produce an unintended consequence of increasing disparities in birth outcomes and could have far-reaching collateral implications, such as misperceptions that infant mortality problems have been solved when part of the population has been left behind, or that reducing racial disparities in birth outcomes is impossible.

Concept mapping is one approach that has been used in community settings to better understand the complexities of social conditions [37-43]. In this project, community team members from a collaborative of six geographically distinct urban areas applied the concept mapping approach to identify actions communities could take to decrease black-white racial disparities in infant mortality. The aims of this project were to gather, synthesize, and report on innovative ideas that other communities could implement to decrease black-white racial disparities in infant mortality. This report highlights results and offers strategies for implementation.

\section{Methods}

Teams comprised of state and local government representatives, federal Healthy Start program representatives, and community coalition members worked to better understand and address racism and its impacts on infant mortality (the Infant Mortality and Racism Action Learning Collaborative (the collaborative) [44]). The collaborative was facilitated by CityMatCH, the Association of Maternal and Child Health Programs (AMCHP), and the National Healthy Start Association (NHSA) (collectively, the partner organizations) with support from the W.K. Kellogg Foundation. Six participating communities (Aurora, CO; Chicago, IL; Columbus, OH; Los Angeles County, CA; Milwaukee, WI; and Pinellas County, FL) were selected through a competitive process for the collaborative. In these communities, infant mortality was at least twice as high in the African-American population as in the white population. The communities also demonstrated the capacity to address the black-white infant mortality gap in their application for participation in the collaborative.

To generate the ideas and better understand which were of greatest necessity and had the greatest potential for action from a community perspective, a mixed methods approach 
called concept mapping was used. This approach and its qualitative and quantitative methods have been well described elsewhere [37, 39, 43, 45-48].

Forty-one (41) participants and 11 advisory group and partner organization staff took part in qualitative informationproducing activities: brainstorming, rating, and sorting. At the outset of the brainstorming session, a focus prompt- "One specific action our community could take to decrease racial disparities in infant mortality is..."-was used to generate ideas. Team participants were divided into four brainstorming groups. Groups were facilitated to ensure that all participants had an opportunity to speak and provide input during the idea generation process. Group interactions were not audio recorded; however, the ideas were posted on a flipchart to ensure that participants' statements were captured accurately. Participants who did not wish to share their ideas in a group setting were allowed to submit their ideas to one of the group facilitators. Participants were allowed to submit as many ideas as they desired. All brainstormed ideas were collected at the end of the session.

Following the brainstorming session, the project's principal investigator and partner organization staff reviewed the items to eliminate duplicate ideas, synthesize ideas that were similar in content and meaning, and prepare a comprehensive list of the unique ideas. The final ideas (action statements) were listed on worksheets for rating and onto index cards for sorting into themes. Rating and organizing the ideas into themes were performed individually by team participants without group interaction. Generated ideas were placed onto two different rating sheets - one for "necessity" and one for "action potential." Necessity was defined as the "need for the specific action to be implemented or undertaken in a community." Action potential was defined as the "potential for action of the specific activity given the availability of resources in a community (money, time, talent, etc.)." All team participants were invited to rate each idea on its own merit regarding necessity and action potential. Scales ranged from 1 to 4 (necessity rating scale: $1=$ not at all necessary, $2=$ somewhat necessary, $3=$ necessary, $4=$ extremely necessary; action potential rating scale: $1=$ no potential for action, $2=$ low potential for action, 3 $=$ moderate potential for action, $4=$ high potential for action). Ideas generated in response to the focus prompt also were placed onto index cards. Team participants were invited to organize the ideas into categories or themes that made sense conceptually to him or her.

Once rating and sorting were completed, the data were entered into a database, verified for accuracy and completeness, and analyzed using the Concept Systems software (Concept Systems Incorporated, Ithaca, NY). Using multidimensional scaling $[49,50]$ and cluster analysis [51], the data were analyzed and a series of visual representations (concept maps) were produced to show the relationships between ideas and the clustering of ideas into themes [39]. Multidimensional scaling techniques were used to produce a number of analyses and zone maps to describe the necessity of and action potential for implementing the ideas. Selected team participants, along with the principal investigator and partner organization staff, refined the analyses, created names for each of the cluster domains, interpreted the maps, discussed the broader themes and meaning of the identified action, and suggested broad applications of knowledge gained from the mapping process.

All analyses and results in this study are based upon team member perceptions and do not necessarily represent the official position of the $\mathrm{CDC}$, CityMatCH, the University of Nebraska Medical Center, AMCHP, NHSA, or any other health department or organization of the authors. The research described in this study was approved by the University of Nebraska Medical Center Institutional Review Board (IRB\#480-09-EP).

\section{Results}

Team participants were highly educated $(75 \%$ had at least a Master's degree), ranged in age from 26 to 73 years (approximately $70 \%$ were 45 years of age or older), and $48 \%$ selfidentified as African-American or Black. Table 1 describes the characteristics of both the team participants and the advisory group members. The collaborative is described in greater detail on the CityMatCH website (http://www.citymatch.org/ projects/partnership-eliminate-disparities-infant-mortalitypedim).

In the brainstorming process, 41 team participants generated over 254 ideas (128 unique ideas) to decrease racial disparities in infant mortality. Table 2 presents each of the action statements by cluster domain. The final set of action statements was analyzed and grouped into 11 clusters (Table 2 and Fig. 1). Each action statement is represented by a dot and numerical reference on the point and cluster maps (Fig. 1). Action statements related to one another are represented by points placed in close proximity. Action statements not related to one another have points placed more distant from one another (e.g., on opposite sides of the map). Likewise, groups of statements that tended to be sorted frequently together are represented by the clusters. The clusters were named based upon their actionable elements and include strategies to:

- Promote knowledge and understanding of the relationship between health and racism

- Develop social messages/marketing about racism and infant mortality

- Improve educational systems and opportunities

- Facilitate community-driven health promotion activities and marketing strategies

- Ensure and improve health services for women across the lifespan 
Table 1 Concept mapping project participant demographics $(n=52)$

\begin{tabular}{llll}
\hline Demographic category & & Number & Percent \\
\hline Age & $<45$ years & 15 & 28.9 \\
& $45-54$ years & 15 & 28.9 \\
& $>54$ years & 22 & 42.3 \\
Self-ascribed race & African-American/Black & 25 & 48.1 \\
& Non-African-American/non-Black & 27 & 51.9 \\
Highest level of education attained & $<$ Masters degree & 13 & 25.0 \\
& Masters degree & 23 & 44.2 \\
Representation on collaborative & $\geq$ Doctoral/MD degree & 16 & 30.8 \\
& Advisory group member & 11 & 21.2 \\
Team distribution of participants & Community team member & Aurora, CO & 71 \\
& Chicago, IL & 6 & 14.6 \\
& Columbus, OH & 5 & 12.2 \\
& Los Angeles County, CA & 8 & 19.5 \\
& Milwaukee, WI & 6 & 14.6 \\
& Pinellas County, FL & 8 & 19.5
\end{tabular}

- Educate and inspire professionals and lay people to take action about racism's impacts on health

- Conduct and disseminate community-informed research

- Address physical and social environments that impact health of the entire community

- Prioritize the allocation of resources for community-based services

- Coordinate and institutionalize strategies that promote equity across all systems

- Create and support legislation and policies that address social determinants of health

Clusters contained as few as 7 and as many as 21 action statements $($ mean=11.6). Participants reviewed the action statements within each of the clusters and discussed how the statements related and the overall area of action implied by the group of statements. Cluster descriptors shown in Fig. 1 and in Table 2 reflect the discussion over a period of 8 months and consensus of the participants. Correlation coefficients of the clusters ranged from 0.17 to 0.90 (Table 3). Degree of correlation was interpreted as negligible $(0.0-0.19)$, weak $(0.20$ $0.49)$, moderate (0.50-0.79), and strong (0.80-1.00).

The 128 final action statements were rated by the participants. The average necessity ratings ranged from 2.17 to 3.73 ; the average action potential ratings ranged from 1.64 to 3.61 . To better understand which statements were believed to be the most necessary and hold the greatest potential for action, we divided the ratings into tertiles and designated the lower tertile as "low," the middle tertile as "moderate," and the upper tertile as "high." In Table 2, the overall perceptions of participants on the necessity and action potential of each statement within its cluster domain are presented. The first sets of columns are the perceptions of all of the team participants (necessity-low $=$ 2.17-2.68; moderate $=2.69-3.21 ;$ and high $=3.22-3.73 ; a c$ tion potential -low $=1.64-2.29$; moderate $=2.30-2.95$; and high $=2.96-3.61$ ). The remaining columns separate out the ratings provided by team participants who self-identified as African-American/Black and as non-African American/Black (African-American/Black: necessity-low =2.24-2.76; moderate $=2.77-3.30 ;$ and high $=3.31-3.83 ;$ action potential low $=1.76-2.39 ;$ moderate $=2.40-3.04$; and high $=3.05-3.68$; non-African-American/non-Black: necessity-low $=2.19$ 2.70; moderate $=2.71-3.21$; and high $=3.22-3.73$; action potential $-\mathrm{low}=1.57-2.23$; moderate $=2.24-2.90$; and high $=2.91-3.57$ ) (Table 2). Generally, the ratings were similar between African-American/Black and non-AfricanAmerican/Black participants.

\section{Discussion}

The statements brainstormed by team participants represent a wide range of actions - from widely recognized, standard strategies to some rather innovative strategies. The inclusion of more widely used strategies suggested that these actions are valued strategies that communities can use to decrease disparities in infant mortality and add to the evidence base. The novel actions represent progressive individual and team thought on viable strategies to reduce racial disparities in infant mortality, particularly at the systems level.

Action statements contained system, community, family, and individual facets of racism and racial disparities that contribute to infant mortality and poor birth outcomes. 
Table 2 Average cluster and statement ratings by perceived impact on decreasing disparities in infant mortality

Cluster descriptor and statements

Rating of perceptions on impact of decreasing disparities

\begin{tabular}{lllll}
\hline $\begin{array}{l}\text { Overall } \\
\text { perception }\end{array}$ & $\begin{array}{l}\text { African-American/ } \\
\text { Black perception } \\
\text { only }\end{array}$ & $\begin{array}{l}\text { Non-African-American/ } \\
\text { non-Black perception } \\
\text { only }\end{array}$ \\
\cline { 1 - 1 } & AP & N $\quad$ AP & N & AP \\
\hline
\end{tabular}

1. Promote knowledge and understanding of the relationship between health and racism

(69) hold public/social marketing awareness campaigns to inform the community, government, and consumers on the impacts of racism on health disparities

(96) provide books and short story materials about "before you become pregnant" at clinics for the public to read

(8) begin education on preconception health from an early age

(37) educate people about racism—what it is, how it operates, what it does, what it "costs"

(40) educate public on ways to reduce preterm births (e.g., signs of early labor, folic acid, P17, stress, etc.)

(38) educate public health students in graduate programs on cultural factors that have a direct correlation with the health of a pregnant woman and her unborn child

(120) train providers on how to educate women about their bodies

(102) provide specific training around Unnatural Causes and provide focus group follow-up to specific conversations

(72) implement age-appropriate and medically accurate health education (i.e., reproductive health, chronic disease, nutrition, etc.) beginning in kindergarten and continuing throughout school (K-12)

(36) educate mental health providers about the impact of racism

(44) encourage reproductive life planning for young men and women

(116) teach cultural competencies in medical school

(86) inform and educate the "front office" personnel about how women feel they are being treated and the effect of communication on patient populations

(94) present and provide opportunities to learn about preconception health practices across many community venues (e.g., female-only groups, youth groups in churches, female organizations in colleges, high school sports teams)

(35) educate home visitation teams, nurses, and community health providers on the impact of race on birth outcomes

(118) teach young children about relationships and family building

(113) require cultural competency training for all health care professionals, especially doctors and nurses

(97) provide education starting in grade school on the historical context and impact of race in the USA

(100) provide in-home education and support to women and their families and friends to assist with addressing resiliency, network

(1) address/educate health providers on the issues of institutional racism as it affects the health outcomes for African-American women and their children

(27) develop a toolkit about racism and infant mortality to increase awareness for dissemination to health care providers, etc.

2. Develop social messages/marketing about racism and infant mortality

(20) create a social marketing campaign focused on safe sleep

(29) develop consistent media messages regarding infant mortality that run continuously throughout the community

(49) engage libraries as stakeholders in raising awareness of social justice issues, racism, disparities, linkages to health outcomes

(90) maintain a multicultural speakers bureau and utilize speakers to help raise awareness of social justice issues, racism, disparities, linkages to health outcomes

(25) create more awareness in those areas of communities that have the highest rates of infant mortality

(46) engage and educate the celebrity community on racism and its impacts on infant mortality so they will bring awareness to the cause

\begin{tabular}{|c|c|c|c|c|c|}
\hline Mod & Mod & Mod & Mod & Mod & Mod \\
\hline Low & High & Low & High & Low & High \\
\hline Mod & Mod & Mod & Mod & Mod & Mod \\
\hline High & High & High & Mod & High & High \\
\hline Mod & High & Mod & High & High & High \\
\hline Mod & High & Mod & Mod & Mod & High \\
\hline Mod & High & Low & Mod & Mod & High \\
\hline Mod & High & Mod & High & Mod & High \\
\hline High & Mod & Mod & Mod & High & Mod \\
\hline Mod & High & High & High & Mod & High \\
\hline High & Mod & Mod & Mod & High & Mod \\
\hline High & High & Mod & Mod & High & High \\
\hline Mod & High & Mod & High & High & High \\
\hline Mod & Mod & Low & Mod & Mod & High \\
\hline High & High & High & High & High & Mod \\
\hline Mod & High & Low & Mod & Mod & High \\
\hline Mod & Mod & Mod & Mod & Mod & Mod \\
\hline Mod & Mod & Mod & Mod & High & Mod \\
\hline Mod & Mod & Low & Mod & Mod & Mod \\
\hline High & High & High & High & High & High \\
\hline High & High & Mod & High & Mod & High \\
\hline
\end{tabular}

$\begin{array}{llllll}\text { Low } & \text { High } & \text { Low } & \text { High } & \text { Low } & \text { High } \\ \text { Mod } & \text { Mod } & \text { Mod } & \text { Mod } & \text { Mod } & \text { Mod } \\ \text { Low } & \text { Mod } & \text { Low } & \text { Mod } & \text { Low } & \text { Mod } \\ \text { Mod } & \text { Mod } & \text { Mod } & \text { Mod } & \text { Low } & \text { Mod } \\ \text { High } & \text { High } & \text { High } & \text { High } & \text { High } & \text { High } \\ \text { Low } & \text { Mod } & \text { Low } & \text { Mod } & \text { Low } & \text { Mod }\end{array}$


Table 2 (continued)

Cluster descriptor and statements
Rating of perceptions on impact of decreasing disparities

\begin{tabular}{lllllll}
\hline $\begin{array}{l}\text { Overall } \\
\text { perception }\end{array}$ & & $\begin{array}{l}\text { African-American/ } \\
\text { Black perception } \\
\text { only }\end{array}$ & & $\begin{array}{l}\text { Non-African-American/ } \\
\text { non-Black perception } \\
\text { only }\end{array}$ & \\
\cline { 1 - 2 } N & AP & N & AP & N & AP \\
Low & Mod & Low & Mod & Low & Mod \\
High & Mod & High & Mod & High & Mod \\
Low & High & Mod & High & Low & High \\
Mod & High & Mod & High & Mod & High \\
Mod & Mod & Mod & Mod & Mod & High \\
Mod & Mod & Low & Mod & Mod & Mod
\end{tabular}

(105) put up bill boards in the community to showcase the connection between racism and infant mortality (e.g., "racism kills babies")

(79) increase educational achievement for African-American families, especially African-American males and low-income children (e.g., Harlem Kids Zone)

(128) write editorials to raise community awareness about disparities and the association of racism with infant mortality

(31) discuss social determinants of health impacting infant mortality

(75) include businesses (e.g., laundromats, grocery stores, barber shops, and beauty salons, taxi companies) in the dissemination of information in infant mortality

(47) engage community members in dialogue about the life course perspective and its application (identify key factors to address)

(45) encourage students to go to college and prepare themselves for the future

3. Improve educational systems and opportunities

(110) replicate successful early childhood programs to meet the needs of all low income children to ensure a foundation for income equality in adulthood

(39) educate public officials and community business leaders to garner support for change

(98) provide educational opportunities for racially oppressed groups of children

(92) offer low cost, secondary educational opportunities to low income, working families

(109) reintroduce health and physical education in the school system

(80) increase racial diversity in medical schools, public health settings, and nursing schools

(34) educate employees of government agencies that provide health services about the discriminatory impacts of their agency policies

4. Facilitate community-driven health promotion activities and marketing strategies

(48) engage community members in message development and design (e.g., use billboards, flyers, the internet, MySpace, buses, PSAs like MADD, and antitobacco groups)

(89) listen to families when they express concerns about health behaviors and practices

(51) engage the whole community to increase awareness of racism, take ownership of it, and take action on/against it

(65) hear the voices of the people we serve and capture disparities from their perspectives

(17) coordinate messaging across all entities and individuals working on infant mortality to ensure consistency

(6) assure that any community planning process engages affected communities (oversample, increase numbers of affected persons)

(77) include more African-American women in the design of program interventions that address infant mortality

(22) create community-wide "cribs for kids" programs with evidence-based "safe-sleep" educational components

5. Ensure and improve health services for women across the lifespan

(56) establish a community health worker program as a tier in the public health infrastructure

(123) use the CenteringPregnancy model as the standard of care for high-risk pregnant women

(7) assure that any perinatal outreach/home visiting program is focused for communities at greatest risk for poor health and social outcomes

(66) hire and train community health workers/home visitors to provide services to pregnant women

(95) promote trust between mothers and medical providers

$\begin{array}{llllll}\text { Mod } & \text { Mod } & \text { Mod } & \text { Mod } & \text { Mod } & \text { Mod } \\ \text { High } & \text { High } & \text { Mod } & \text { High } & \text { High } & \text { Mod } \\ \text { Mod } & \text { Low } & \text { Mod } & \text { Mod } & \text { High } & \text { Low } \\ \text { Mod } & \text { Low } & \text { Mod } & \text { Mod } & \text { Mod } & \text { Low } \\ \text { Mod } & \text { Mod } & \text { Mod } & \text { Mod } & \text { High } & \text { Mod } \\ \text { High } & \text { Mod } & \text { Mod } & \text { Mod } & \text { High } & \text { Mod } \\ \text { High } & \text { Mod } & \text { Mod } & \text { Mod } & \text { High } & \text { High }\end{array}$

$\begin{array}{llllll}\text { Mod High Mod } & \text { High } & \text { High } & \text { High } \\ \text { Mod High } & \text { Mod } & \text { High } & \text { Mod } & \text { High } \\ \text { Mod } & \text { Mod } & \text { High } & \text { Mod } & \text { High } & \text { Mod } \\ \text { High High High } & \text { High } & \text { High } & \text { High } \\ \text { Mod Mod Mod } & \text { Mod } & \text { Mod } & \text { Mod } \\ \text { High High High } & \text { High } & \text { High } & \text { High } \\ \text { High High High } & \text { High } & \text { High } & \text { High } \\ \text { Low Mod Low } & \text { Mod } & \text { Low } & \text { High }\end{array}$

$\begin{array}{llllll}\text { Low } & \text { Mod } & \text { Mod } & \text { Mod } & \text { Low } & \text { Mod } \\ \text { Low } & \text { Mod } & \text { Low } & \text { Mod } & \text { Low } & \text { Mod } \\ \text { High } & \text { High } & \text { Mod } & \text { High } & \text { High } & \text { High } \\ \text { Mod } & \text { High } & \text { Mod } & \text { High } & \text { Mod } & \text { Mod } \\ \text { Mod } & \text { Mod } & \text { Mod } & \text { Mod } & \text { Mod } & \text { Mod }\end{array}$


Table 2 (continued)

\begin{tabular}{|c|c|c|c|c|c|c|}
\hline & \multirow{2}{*}{\multicolumn{2}{|c|}{$\begin{array}{l}\text { Overall } \\
\text { perception }\end{array}$}} & & & & \\
\hline & & & \multicolumn{2}{|c|}{$\begin{array}{l}\text { African-American/ } \\
\text { Black perception } \\
\text { only }\end{array}$} & \multicolumn{2}{|c|}{$\begin{array}{l}\text { Non-African-American/ } \\
\text { non-Black perception } \\
\text { only }\end{array}$} \\
\hline & $\mathrm{N}$ & $\mathrm{AP}$ & $\mathrm{N}$ & $\mathrm{AP}$ & $\mathrm{N}$ & $\mathrm{AP}$ \\
\hline $\begin{array}{l}\text { (64) have a higher proportion of affected community members as participants in } \\
\text { group coalitions }\end{array}$ & High & High & Mod & High & High & High \\
\hline $\begin{array}{l}\text { (125) utilize the life course theory as a foundation to improve birth outcomes in the } \\
\text { African-American/Black population }\end{array}$ & Mod & High & Mod & Mod & Mod & Mod \\
\hline
\end{tabular}

6. Educate and inspire professionals and lay people to take action about racism's impacts on health

(115) rotate medical and nursing students through community health centers as a part of the cultural competency training

(104) pursue mandatory curriculum in medical and nursing schools on the role of MDs and RNs in eliminating racism and disparities

(112) require continuing education for relicensure for all health care providers on interpersonal/institutional racism

(103) provide training and education for staff of medical and nursing schools making the connection between racism and infant mortality

(119) teach youth, women. and men to advocate for their health rights throughout their lifespan

(122) use public transportation as a medium for educating the public on racism, racial disparities, and infant mortality

(30) discuss/teach males about their role in preconception health

(32) discuss the historical and present context of racism and its impacts in our public health agencies

(28) develop and implement middle school and high school student curricula on the relationship/impact of racism, racial disparities, and health

(12) conduct community conversations in nontraditional settings

(101) provide opportunities for men/fathers to understand the impact of racial disparities in infant mortality and the related impacts on their home, family, and community

(78) include screening questions on perceived racism and stress in prenatal visits

(117) teach stress reduction techniques to women

(126) utilize viewings of Unnatural Causes/When the Bough Breaks to create dialogues and to enhance the understanding of racism and its impact on infant mortality

7. Conduct and disseminate community-informed research

(106) recognize community-driven and community-based evidence in addition to published evidence

(14) conduct survey on what community wants/ways to improve health outcomes

(124) utilize community-based evidence to build programs - do not just wait for recognized, evidence-based practices

(53) ensure research includes/controls for race, class, gender, income

(54) ensure that FIMR data is collected, analyzed, translated, and disseminated timely and to the community

(73) implement community participatory research techniques to develop and implement strategic plans

(70) identify and support all of the factors that can make African-American families resilient

(16) convene home health parties to allow residents to strategize on developing programs to address racial disparities in their community

(13) conduct public health research which identifies strategies to address racial disparities

(11) conduct an analysis of your infant mortality rate for your target population (PPOR)

(50) engage the faith community in a common message about disparities and social justice

(62) gather men/fathers opinions, views, experiences on infant mortality

(15) contact faith-based organizations to engage their congregations

$\begin{array}{llllll}\text { Mod } & \text { Mod } & \text { Mod } & \text { Mod } & \text { Mod } & \text { High } \\ \text { High } & \text { Mod } & \text { High } & \text { Mod } & \text { High } & \text { Mod } \\ \text { Mod } & \text { Mod } & \text { Mod } & \text { Mod } & \text { Mod } & \text { Mod } \\ \text { High } & \text { Mod } & \text { High } & \text { Mod } & \text { High } & \text { High } \\ \text { High } & \text { High } & \text { High } & \text { High } & \text { High } & \text { High } \\ \text { Low } & \text { Mod } & \text { Low } & \text { Mod } & \text { Low } & \text { Mod } \\ \text { High } & \text { High } & \text { High } & \text { High } & \text { High } & \text { High } \\ \text { High } & \text { High } & \text { Mod } & \text { Mod } & \text { High } & \text { High } \\ \text { Mod } & \text { Mod } & \text { Mod } & \text { Mod } & \text { Mod } & \text { Mod } \\ \text { Mod } & \text { High } & \text { Mod } & \text { High } & \text { Mod } & \text { High } \\ \text { High } & \text { Mod } & \text { High } & \text { High } & \text { Mod } & \text { Mod } \\ \text { Mod } & \text { High } & \text { Mod } & \text { High } & \text { Mod } & \text { High } \\ \text { Mod } & \text { High } & \text { Mod } & \text { High } & \text { Mod } & \text { High } \\ \text { Mod } & \text { High } & \text { Mod } & \text { High } & \text { Mod } & \text { High }\end{array}$

$\begin{array}{llllll}\text { Mod } & \text { High } & \text { High } & \text { High } & \text { Mod } & \text { High } \\ \text { Mod } & \text { High } & \text { High } & \text { High } & \text { Mod } & \text { High } \\ \text { Mod } & \text { Mod } & \text { Mod } & \text { Mod } & \text { Low } & \text { Mod } \\ \text { Mod } & \text { Mod } & \text { Mod } & \text { Mod } & \text { Mod } & \text { Mod } \\ \text { Mod } & \text { Mod } & \text { Low } & \text { Mod } & \text { Mod } & \text { Mod } \\ \text { Low } & \text { Mod } & \text { Low } & \text { Mod } & \text { Low } & \text { Mod } \\ \text { Mod } & \text { Mod } & \text { Mod } & \text { Low } & \text { Mod } & \text { Mod } \\ \text { Low } & \text { Mod } & \text { Mod } & \text { Mod } & \text { Low } & \text { Mod } \\ \text { High } & \text { High } & \text { Mod } & \text { High } & \text { High } & \text { High } \\ \text { Mod } & \text { High } & \text { Mod } & \text { High } & \text { Mod } & \text { High } \\ \text { Low } & \text { High } & \text { Low } & \text { High } & \text { Mod } & \text { High } \\ \text { Mod } & \text { High } & \text { Mod } & \text { High } & \text { Mod } & \text { High } \\ \text { Mod } & \text { High } & \text { Mod } & \text { High } & \text { Mod } & \text { High }\end{array}$


Table 2 (continued)

Cluster descriptor and statements

Rating of perceptions on impact of decreasing disparities

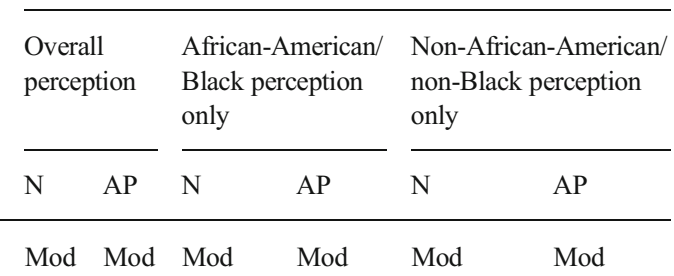

(33) disseminate findings of progress/strategies to eliminate racism and rank communities in a report card on racism

8. Address physical and social environments that impact health of the entire community

(82) increase stable housing for pregnant women and infants and their families

(58) examine the impact of industry placement in community neighborhoods and the resulting impacts (e.g., toxins) on health

(114) require insurance companies to have pay and performance measures on cultural competence in medical and dental practices

(99) provide for basic family needs to reduce racial stress for both women and men that impact birth outcomes

(71) identify cost/benefit savings to insurance companies, hospitals, and doctors for addressing contributing factors to high-risk infant mortality

(59) examine the legal system practices (i.e., bail, bond, lawyer expense) that keep fathers in jail and not at home with their families before trial

(5) assure that all neighborhoods are safe and walkable

(2) adopt Michael Lu's 12-Point Plan

9. Prioritize the allocation of resources for community-based services

(85) influence public funding (e.g., federal and state grants) decisions to supplement efforts to address racism and disparities

(52) ensure private and public health insurance reimbursement for screening and referral of women and families needing mental/emotional health services

(91) make family planning services and contraceptives widely available and affordable to support planned pregnancies

(84) increase the availability of and easy access to fresh fruits and vegetables in communities

(21) create affordable transportation systems that link neighborhoods and people with jobs

(24) create jobs in underserved neighborhoods where jobs are not readily available

(81) increase resources available to clinics/hospitals that reach low-income families like mental health services, health education classes with incentives

(61) fund and implement a system of pre- and interconceptional care services for women of reproductive age

(88) leverage/target existing community resources to communities of greatest need

(68) hold Medicaid HMOs accountable for birth outcomes

(63) get businesses to recognize the cost factors (savings) when their employees (male and female) have prenatal care and the outcome of having healthy babies

(18) create a 1-stop neighborhood health center for preventive care, immunizations, well care check-ups, etc.

(87) involve large corporations to fund public awareness campaigns of racism, racial disparities, and infant mortality

10. Coordinate and institutionalize strategies that promote equity across all systems

(57) establish an education/job/housing comprehensive initiative for communities of need

(26) develop a system of maternal and child health that is connected by mission, not by source of funding

(121) unify all community groups in a city working on separate infant mortality issues, plans, grants

(19) create a health department platform for addressing racism

(108) reduce the availability of alcohol and tobacco in communities

\begin{tabular}{|c|c|c|c|c|}
\hline High & Low & High & Mod & High \\
\hline Low & Mod & Mod & Low & Low \\
\hline Mod & Low & Low & Low & Mod \\
\hline Mod & Low & Mod & Mod & Mod \\
\hline Mod & High & Mod & Mod & Mod \\
\hline Low & Low & Low & Low & Mod \\
\hline Mod & Low & Mod & Mod & Mod \\
\hline Mod & Mod & Mod & Mod & Mod \\
\hline
\end{tabular}

$\begin{array}{llllll}\text { High } & \text { Mod } & \text { Mod } & \text { Mod } & \text { High } & \text { Mod } \\ \text { Mod } & \text { Low } & \text { Mod } & \text { Low } & \text { High } & \text { Low } \\ \text { Mod } & \text { Mod } & \text { Mod } & \text { Mod } & \text { High } & \text { Mod } \\ \text { High } & \text { Mod } & \text { High } & \text { Mod } & \text { High } & \text { Mod } \\ \text { Mod } & \text { Low } & \text { Mod } & \text { Low } & \text { High } & \text { Low } \\ \text { High } & \text { Low } & \text { High } & \text { Low } & \text { High } & \text { Low } \\ \text { Mod } & \text { Mod } & \text { High } & \text { Mod } & \text { Mod } & \text { Mod } \\ \text { Mod } & \text { Mod } & \text { Mod } & \text { Mod } & \text { High } & \text { Mod } \\ \text { High } & \text { Mod } & \text { High } & \text { Mod } & \text { Mod } & \text { Mod } \\ \text { Mod } & \text { Low } & \text { Low } & \text { Low } & \text { Mod } & \text { Low } \\ \text { Mod } & \text { Mod } & \text { Mod } & \text { Mod } & \text { High } & \text { Mod } \\ \text { Mod } & \text { Mod } & \text { Mod } & \text { Mod } & \text { Mod } & \text { Mod } \\ \text { Mod } & \text { Mod } & \text { Mod } & \text { Low } & \text { Mod } & \text { Mod }\end{array}$

$\begin{array}{llllll}\text { Mod } & \text { Low } & \text { Mod } & \text { Mod } & \text { High } & \text { Low } \\ \text { Mod } & \text { Low } & \text { Mod } & \text { Low } & \text { Mod } & \text { Mod } \\ \text { Mod } & \text { Mod } & \text { Mod } & \text { Mod } & \text { Mod } & \text { Mod } \\ \text { Mod } & \text { Mod } & \text { Mod } & \text { Mod } & \text { High } & \text { Mod } \\ \text { Low } & \text { Low } & \text { Mod } & \text { Low } & \text { Low } & \text { Low }\end{array}$


Table 2 (continued)

\begin{tabular}{|c|c|c|c|c|c|c|}
\hline & \multicolumn{2}{|c|}{$\begin{array}{l}\text { Overall } \\
\text { perception }\end{array}$} & \multicolumn{2}{|c|}{$\begin{array}{l}\text { African-American/ } \\
\text { Black perception } \\
\text { only }\end{array}$} & \multicolumn{2}{|c|}{$\begin{array}{l}\text { Non-African-American } \\
\text { non-Black perception } \\
\text { only }\end{array}$} \\
\hline & $\mathrm{N}$ & $\mathrm{AP}$ & $\mathrm{N}$ & $\mathrm{AP}$ & $\mathrm{N}$ & AP \\
\hline $\begin{array}{l}\text { (3) adopt the WHO } 3 \text { action steps to address the social determinants of health on local, state, } \\
\text { and national levels }\end{array}$ & Mod & Mod & Mod & Mod & Mod & Mod \\
\hline $\begin{array}{l}\text { (9) broaden the definition of reproductive health to reproductive justice (i.e., it is not just } \\
\text { contraception and abortion) }\end{array}$ & Low & Mod & Low & Mod & Low & Low \\
\hline (67) hold mandatory yearly hearings on status of health disparities and racism in the community & Mod & Mod & Low & Mod & Low & Mod \\
\hline (10) build neighborhoods that allow for social cohesion and support social networks & Mod & Low & Mod & Low & High & Low \\
\hline $\begin{array}{l}\text { (74) improve funding of educational systems to reduce disparities in school financial support and } \\
\text { opportunities for students }\end{array}$ & Mod & Low & Mod & Low & High & Low \\
\hline
\end{tabular}

11. Create and support legislation and policies that address social determinants of health

(93) pass health care legislation that would provide health care for all citizens

(127) work with local, state, and national policymakers to develop and enact laws related to health equity and health care equity for all citizens regardless of SES, race, ethnicity, geographic location, community, or neighborhood

(42) enact legislation and funding to support successful reentry for formally incarcerated men and women

(4) advocate for policy change to promote health care coverage and preconception health education during health encounters

(43) enact mandatory paid sick leave for all workers

(76) include government officials in efforts as full participants throughout the process

(41) elect officials that have a commitment to reducing disparities

(23) create family supporting jobs for low-skilled workers

(107) reduce poverty levels by creating good jobs and ensuring people have skills

(55) establish a 100-year commitment to address this issue (e.g., the Native American 5

Generations Plan, forest/timber industries 100-year plans)

(83) increase support for breastfeeding in workplaces and schools

(111) require a state/county/local collaborative for addressing racism, racial disparities, infant mortality that includes key community leaders and gatekeepers

(60) examine the racial disparity in sentencing and the criminal justice system

$\begin{array}{llllll}\text { High } & \text { Mod } & \text { High } & \text { Mod } & \text { High } & \text { Low } \\ \text { High } & \text { Mod } & \text { High } & \text { Mod } & \text { High } & \text { Mod } \\ \text { Low } & \text { Low } & \text { Mod } & \text { Low } & \text { Low } & \text { Low } \\ \text { Mod } & \text { Mod } & \text { Mod } & \text { Mod } & \text { High } & \text { Mod } \\ \text { Low } & \text { Low } & \text { Low } & \text { Low } & \text { Mod } & \text { Low } \\ \text { Mod } & \text { Mod } & \text { Mod } & \text { Mod } & \text { Mod } & \text { Mod } \\ \text { High } & \text { Mod } & \text { High } & \text { Mod } & \text { High } & \text { Mod } \\ \text { Mod } & \text { Low } & \text { Mod } & \text { Low } & \text { Mod } & \text { Low } \\ \text { Mod } & \text { Low } & \text { Mod } & \text { Low } & \text { Mod } & \text { Low } \\ \text { Low } & \text { Low } & \text { Low } & \text { Low } & \text { Low } & \text { Low } \\ \text { Mod } & \text { Mod } & \text { Mod } & \text { Mod } & \text { Mod } & \text { Mod } \\ \text { Mod } & \text { Mod } & \text { Mod } & \text { Mod } & \text { Mod } & \text { Mod } \\ \text { Mod } & \text { Mod } & \text { Mod } & \text { Mod } & \text { Mod } & \text { Mod }\end{array}$

The 128 statements are presented within their clusters and the parenthetical numbers refer to the actual statement number and can be used to link the table information to Fig. 2. The numbers do not have any substantive meaning; they are merely for identification of the individual statements. Ratings (necessity, action potential) represent how strongly each statement is thought to have potential impact on reducing disparities in infant mortality. Ratings were split into tertiles and computed for community team members only, African-American/Black only, and non-African-American/non-Black only. Community teams: necessity - low= 2.17-2.68; moderate $=2.69-3.21$; and high $=3.22-3.73$; action potential $-\mathrm{low}=1.64-2.29$; moderate $=2.30-2.95$; and high $=2.96-3.61$. African-American/ Black: necessity - low $=2.24-2.76$; moderate $=2.77-3.30$; and high $=3.31-3.83$; action potential - low $=1.76-2.39$; moderate $=2.40-3.04$; and high $=3.05-$ 3.68. Non-African-American/non-Black: necessity - low $=2.19-2.70$; moderate $=2.71-3.21$; high $=3.22-3.73$; action potential-low $=1.57-2.23$; moderate $=$ 2.24-2.90; and high $=2.91-3.57$

$N$ necessity, $A P$ action potential, $P S A s$ public service announcements, MADD Mothers Against Drunk Driving, FIMR fetal and infant mortality review, PPOR Perinatal Periods of Risk, HMO health maintenance organization, SES socioeconomic status

Examples of action statements that communities could promote or initiate to address disparities at the systems level included:

- Working with local, state, and national policymakers to develop and enact health equity and health care equity laws
- Educating clinical and mental health providers about racism and its impact on birth outcomes

- Creating opportunities for clinical rotations in community health centers for the poor and medically underserved

- Requiring mandatory curriculum and continuing education for clinicians regarding racism and the different levels of racism 


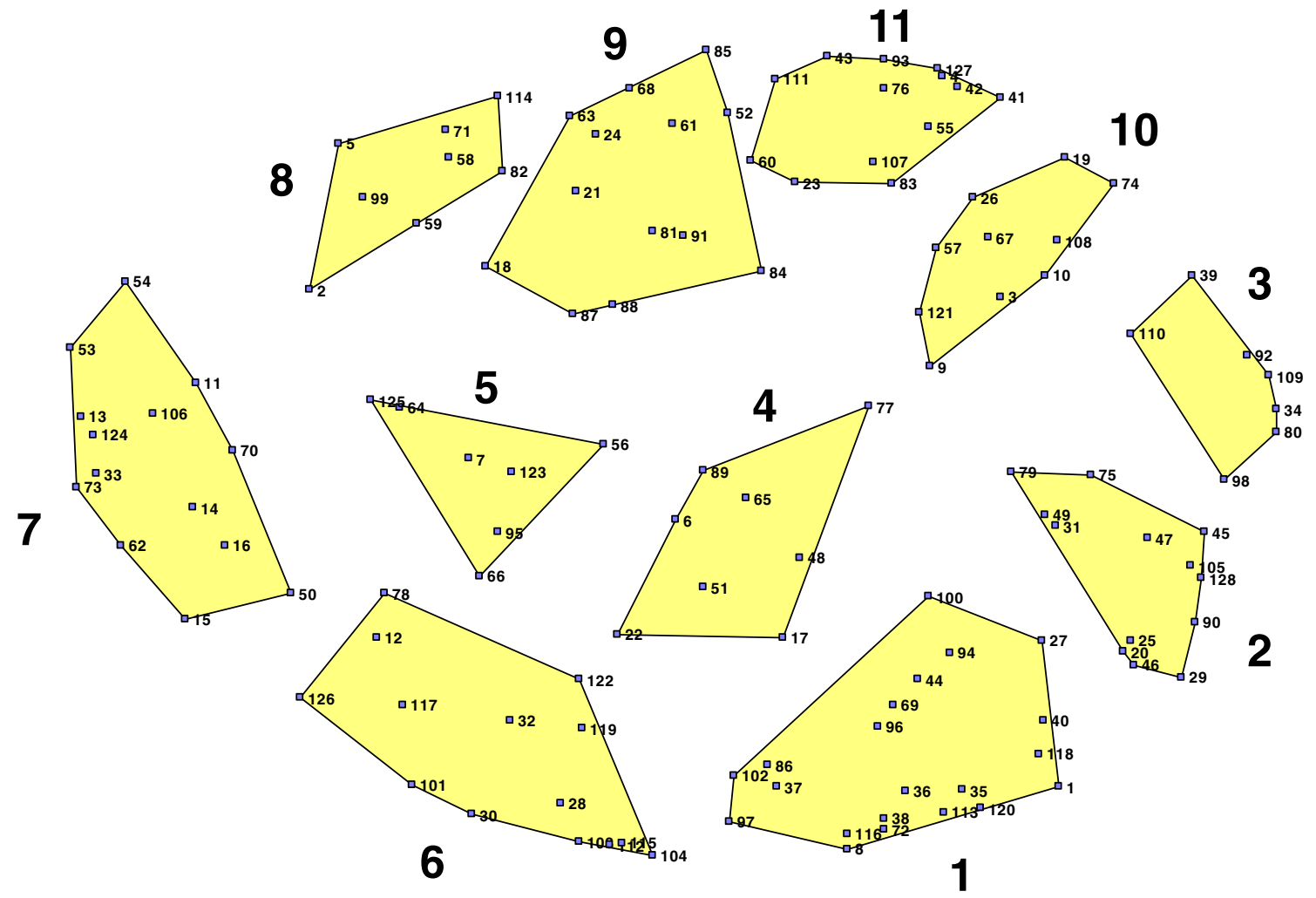

Fig. 1 Thematic cluster map. Cluster theme descriptors: 1 Promote knowledge and understanding of the relationship between health and racism, 2 develop social messages/marketing about racism and infant mortality, 3 improve educational systems and opportunities, 4 facilitate community-driven health promotion activities and marketing strategies, 5 ensure and improve health services for women across the lifespan, 6 educate and inspire professionals and lay people to take action about

\section{Community-level action statements included:}

- Educating people about racism, increasing awareness around infant mortality

- Taking part in community planning processes racism's impacts on health, 7 conduct and disseminate community-informed research, 8 address physical and social environments that impact health of the entire community, 9 prioritize the allocation of resources for community-based services, 10 coordinate and institutionalize strategies that promote equity across all systems, and 11 create and support legislation and policies that address social determinants of health

- Creating opportunities for community viewings and facilitated discussions of Unnatural Causes

- Developing middle school and high school curricula on the relationships and impacts of racism, racial disparities, and health

Table 3 Correlation coefficients between necessity and action potential by cluster

\begin{tabular}{ll}
\hline Cluster no. & Cluster theme descriptor \\
\hline 1 & Promote knowledge and understanding of the relationship between health and racism \\
2 & Develop social messages/marketing about racism and infant mortality \\
3 & Improve educational systems and opportunities \\
4 & Facilitate community-driven health promotion activities and marketing strategies \\
5 & Ensure and improve health services for women across the lifespan \\
6 & Educate and inspire professionals and lay people to take action about racism's impacts on health \\
7 & Conduct and disseminate community-informed research \\
8 & Address physical and social environments that impact health of the entire community \\
9 & Prioritize the allocation of resources for community-based services \\
10 & Coordinate and institutionalize strategies that promote equity across all systems \\
11 & Create and support legislation and policies that address social determinants of health \\
\hline
\end{tabular}

Degree of correlation was interpreted as negligible $(0.0-0.19)$, weak $(0.20-0.49)$, moderate $(0.50-0.79)$, and strong $(0.80-1.00)$

The bolded values represent those that are more significant 
- Taking part in and using community-based research

Individual-level action statements that could be promoted and supported by communities included:

- Teaching and using stress reduction techniques

- Teaching youth, women, and men to advocate for their health rights

- Hearing the voices of the people we serve

- Using the cultural humility framework

We anticipated that there might be differences in how statements were rated between participants who selfidentified as African-American/Black and non-AfricanAmerican/Black. The ratings, however, were similar. We believe that the shared racism training and experiences of the participants over the 18-month collaborative likely influenced the participants' perceptions in rating statements' necessity and action potential. Participants received specific training about race and racism from the People's Institute and used a variety of educational tools, including Race: the Power of an Illusion (http://www.pbs.org/race/000_General/000_00Home.htm) and Unnatural Causes (http://www. unnaturalcauses.org/), to broaden their own understanding of race and racism and its impact on birth outcomes. The participants used a common definition of racism and an understanding of its different forms. As a group, the participants worked towards an understanding of one's own connection to institutional racism and its impact on his/her work and an understanding of the historical context for how racial classifications in the USA came to be and how they are maintained. It is possible that these shared experiences played a role in how participants rated statements.

In traditional concept mapping, clusters typically are given a three- to five-word descriptor [39]. However, participants in this project opted to choose descriptors that were action oriented. The themes that emerged from the cluster analysis represent an "executive summary" of the actionable elements considered necessary for reducing racial disparities in infant mortality (see Fig. 1 legend). While cluster naming is usually a minor step in the concept mapping process, for this project, the participants spent considerable time analyzing the content of each cluster and trying to gain an understanding of how the individual statements were related. The end result of this process was a list of 11 areas which can be used as a general guide for community planning in addressing racism and its impact on birth outcomes.

Clustered domains that were viewed as highly necessary (Fig. 2; clusters 1, 3, 4, 6, 9, and 11) often were associated with education. For example, clusters 1, 3, and 6 contain elements that promote the education of both consumers and professionals and reform of educational systems. Clusters 4 and 9 contain strategies for community-driven health promotion activities and actions that are needed for effective allocation of community-based resources. Cluster 11 was the primary domain for actions around policy and legislation for health equity and addressing the social determinants of health. The general consensus of the participants was that the educational aspects are crucial to a foundational understanding of racism, how inequities are created and sustained, and how racism impacts the health and well-being of populations. In addition, the participants felt that policy and legislation would be essential for promoting and producing health equity.

Clustered domains that had high action potential (Fig. 3, below the line) were interpreted as ongoing or easily implemented groups of ideas. These clusters often contained actions that individuals or community stakeholders could do with few or no resources, such as increasing knowledge about racism, racial disparities, and how racism influences health outcomes. Nevertheless, many activities that may already be ongoing in a community - health promotion activities, community-based research, programs for improving health services - may benefit from expansion, greater community member participation, and an equity-informed approach.

Clusters that had low action potential were interpreted as containing elements that would require broader, longer term policy, institutional or system-wide changes, and that might require greater resources to initiate, implement, and sustain (Fig. 3, above the line). Low action potential clusters dealt with the need to change educational systems, improve physical and social environments which impact the health of individuals, re-prioritize and allocate resources and community assets, coordinate and institutionalize equity strategies, and create policies and legislation that promote health equity and address social determinants of health. The clusters that contained many of the system/institutional level statements (i.e., clusters $3,8,9,10$, and 11) were deemed necessary but often were perceived to have low action potential. The work of "undoing" racism and its associated impacts on infant mortality is an important, large-scale work that neccessitates widespread policy changes and policy implementation. Participants recognized the need to engage policy makers, legislators, and other elected officials at the beginning of local efforts to reduce racism. Participants also felt it would be necessary to educate their elected officials on how racism contributed to health disparities and how it is related to infant mortality.

The participants also looked at zone maps for each of the domain clusters (data not shown). In cluster 1 (items related to promoting knowledge and understanding of the relationship between health and racism), participants interpreted the elements that scored high in both action potential and necessity as practical concrete approaches that could create larger and lasting changes in practice and policy. With regard to cluster 2 
Fig. 2 Necessity cluster rating map

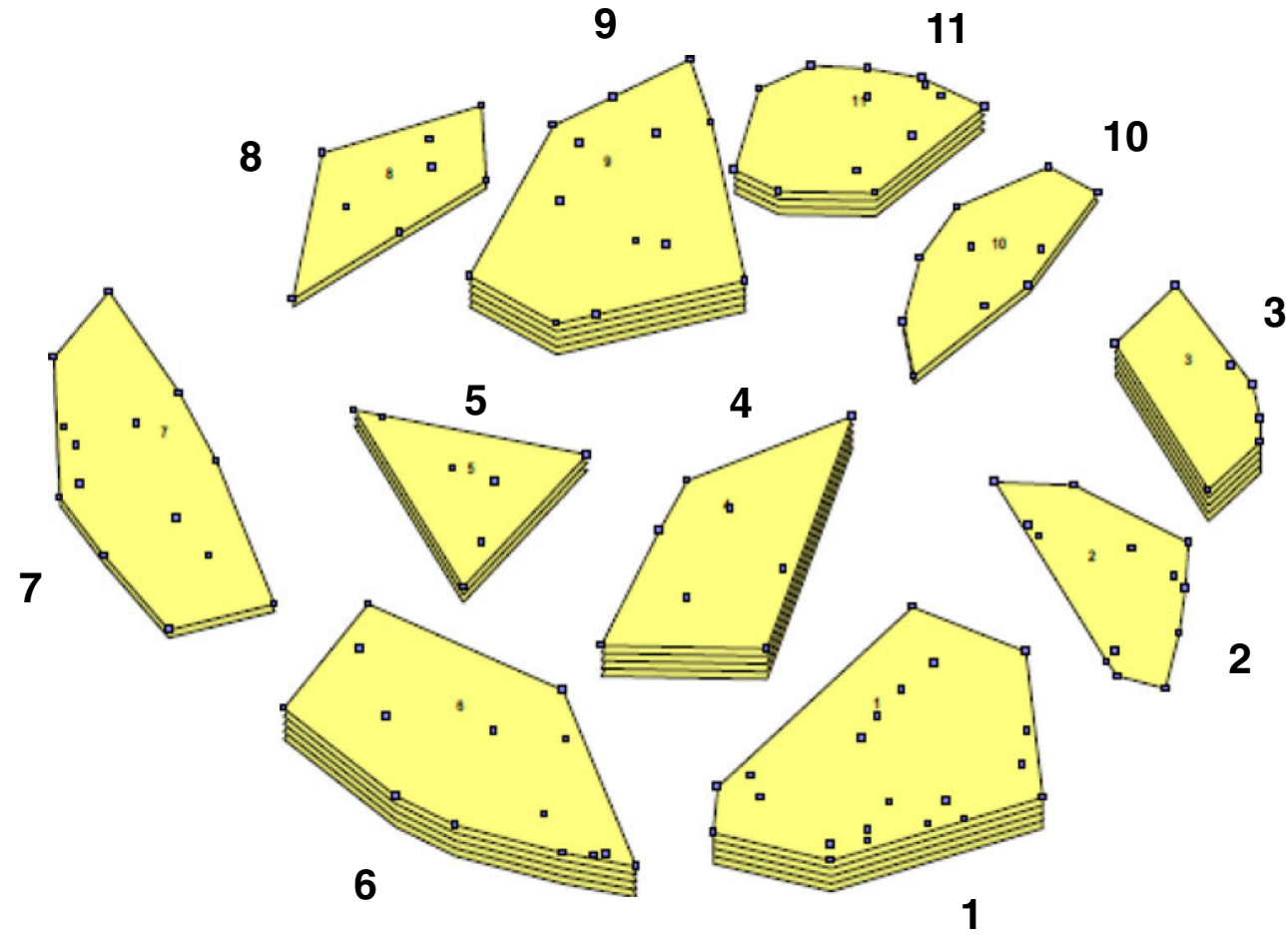

(developing social messages and marketing about racism and infant mortality), elements that scored high in both action potential and necessity were generally actions that could be achieved by community-level dialogues using existing discussion tools and films for initiating facilitated discussion. The elements rated as high action potential also were viewed as having existing models or best practices and information that could be used for immediate development and consumption within a community. Statements in clusters 3 and 6 that scored high in both action potential and necessity dealt with the education of government employees, public officials, and health care providers, as well as the general public on the

Fig. 3 Action potential cluster rating map

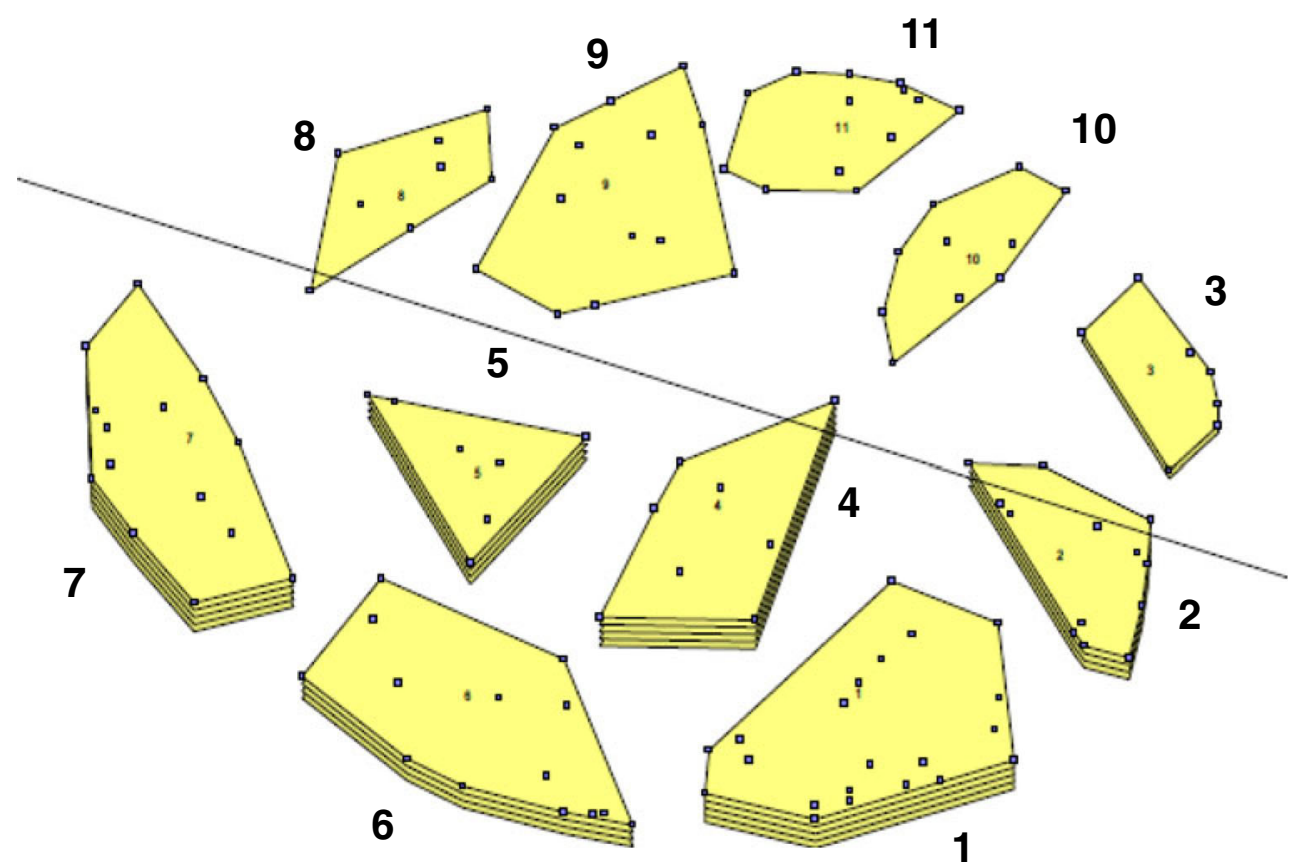


historical and present context of racism, the impact of different types of racism on an individual, and the impact of racism and discrimination in systems of care on the health of individuals. Clusters 4, 5, and 7 had high scoring elements around community engagement, the inclusion of community membersparticularly African-American women-in assessment, planning, design, and communication processes, and the need for public health research to identify strategies to address racial disparities.

We identified three immediate applications for the information generated during the concept mapping process. First, many communities could conduct needs assessments or environmental scans of the types of services or benefits that community members desire or that are being provided by various providers or stakeholders. The action statements could be compared to the needs assessment or environmental scan results to identify gaps in, redundancies, and unrecognized or underutilized services or benefits. Thus, the action statements and their domains can be used as a starting point for a community and provider discussion, planning, and assessment. Second, the action statements could be used by communities as an addendum to the strategies and action steps in the National Stakeholder Strategy for Achieving Health Equity developed by the National Partnership for Action [52].

Third, the action statements can be used to further the work of the Perinatal Periods of Risk (PPOR) approach [53-56]. PPOR, a comprehensive approach to help communities use data to reduce infant mortality, was designed for use in urban areas with high infant mortality rates. PPOR brings stakeholders together from many sectors to build consensus and partnership based on community data and provides an analytic framework and steps for investigating and addressing the specific local causes of fetal and infant mortality and disparities in vulnerable populations. One aspect of the PPOR process characterizes the period of risk by birthweight and age at death. For each of the four periods of risk (maternal health/prematurity, maternal care, newborn care, and infant health), certain viable solutions or preventive actions are identified. The action statements generated by concept mapping can be directly transferred to the periods of risk map as potential solutions or preventive measures. An example is shown in Table 4.

\section{Strengths}

To our knowledge, this is the first time that concept mapping has been used as a technique to explore racial disparities and infant mortality. In addition, the concept mapping technique is uniquely suited for engaging the participation of people from all backgrounds, educational levels, and ages. As described in
Green and Aarons, the conceptual framework of concept mapping helps capture diverse perspectives and assess levels of agreement between or among different types of stakeholders [57].

\section{Limitations}

One potential limitation of this project is that the qualitative portions with team participants were conducted within an extremely narrow window of time (less than 6 h). Normally, brainstorming, rating, and sorting are conducted over a period of days or weeks. However, the final meeting of the collaborative presented an ideal opportunity to capture the momentum and passion of the participants. Some participants did, however, find it difficult to shift focus from the ongoing work of the collaborative to the concept mapping project. Another potential limitation is the generalizability of the information produced. While the intent was to produce information that communities could use to reduce disparities in infant mortality, the statements and analyses were conducted by individuals from communities with significant infant mortality disparities but who were highly educated and deeply experienced in public health. Thus, the information may not be wholly generalizable to all communities nor may it be considered as wholly community informed. Each of the communities participating in the collaborative contributed to a final report that highlighted the specific activities in which they engaged. This report can be found at: http:// webmedia.unmc.edu/Community/CityMatch/HealthEquity/ TakingFirstStepBooklet.pdf.

Team participants also struggled with the emphasis of the focus prompt on "reducing racial disparities in infant mortality" rather than "reducing racism and its impact on infant mortality." As a collaborative, there was special emphasis on both racism and racial disparities. In hindsight, the team participants felt that the focus prompt and concept mapping process should have explored racism and potential solutions to decreasing racism and its impact on infant mortality.

\section{Recommendations}

For communities who are initiating dialogues and working on addressing racism and its impacts on infant mortality, participants recommended that communities focus their efforts in three of the key domains: promoting knowledge and understanding of the relationship between health and racism; developing social messages and marketing about racism and infant mortality; and facilitating community-driven health promotion activities and marketing strategies. Participants underscored the need for education around racism - what it is, why the process in the USA is unique, how it is manifested, 
Table 4 Perinatal periods of risk (PPOR) solutions map

\begin{tabular}{|c|c|c|}
\hline Perinatal period of risk & Traditional solutions & Example of inclusion of concept mapping action statements \\
\hline Maternal health/prematurity & $\begin{array}{l}\text { - Address chronic diseases } \\
\text { - Address harmful health behaviors } \\
\text { - Ensure perinatal care } \\
\text { - Etc. }\end{array}$ & $\begin{array}{l}\text { - Make family planning services and contraceptives widely available and } \\
\text { affordable to support planned pregnancies } \\
\text { - Optimize preconception health } \\
\text { - Ensure access to quality prenatal/perinatal care } \\
\text { - Reduce/quit smoking } \\
\text { - Reduce the availability of alcohol and tobacco in communities }\end{array}$ \\
\hline Maternal care & $\begin{array}{l}\text { - Ensure prenatal care } \\
\text { - Ensure high-risk referrals } \\
\text { - Ensure appropriate obstetric care } \\
\text { - Etc. }\end{array}$ & $\begin{array}{l}\text { - Access to quality prenatal and obstetric care } \\
\text { - Increase women's knowledge about signs of early labor } \\
\text { - Improve systems for high-risk referrals } \\
\text { - Educate mental health providers about the impact of racism } \\
\text { - Include screening questions on perceived racism and stress in prenatal visits }\end{array}$ \\
\hline Newborn care & $\begin{array}{l}\text { - Ensure perinatal management } \\
\text { - Ensure neonatal care } \\
\text { - Provide pediatric surgery } \\
\text { - Etc. }\end{array}$ & $\begin{array}{l}\text { - Increase stable housing for pregnant women and infants and their families } \\
\text { - Require continuing education for relicensure for all health care providers } \\
\text { on interpersonal/institutional racism } \\
\text { - Educate home visitation teams, nurses, and community health providers on } \\
\text { the impact of race on birth outcomes }\end{array}$ \\
\hline Infant health & $\begin{array}{l}\text { - Protect against sleep-related deaths } \\
\text { - Prevent injuries } \\
\text { - Prevent/treat infections } \\
\text { - Etc. }\end{array}$ & $\begin{array}{l}\text { - Improve knowledge/practices to address sleep-related deaths, injuries, early } \\
\text { childhood infections } \\
\text { - Increase support for breastfeeding in workplaces and schools } \\
\text { - Create more awareness in those areas of communities that have the highest } \\
\text { rates of infant mortality } \\
\text { - Ensure that FIMR data is collected, analyzed, translated, and disseminated } \\
\text { timely and to the community }\end{array}$ \\
\hline
\end{tabular}

FIMR fetal and infant mortality review

and how it is perpetuated - and how personally mediated, individual and institutional racism affects health [58]. Communities have used a number of methods and venues to initiate these dialogues, but participants found that small, diverse community groups who viewed episodes of Unnatural Causes and/or Race: the Power of an Illusion with a facilitated discussion to be particularly useful.

\section{Public Health Implications}

Concept mapping proved to be a readily adaptable approach to explore the complexities of racial disparities and infant mortality. The discussion of racial disparities may be emotionally charged as community leaders, seeing the problem through their own lenses, attempt to determine feasible approaches to tackling the issue. Grouping strategies into clusters and determining their action potentials are steps that simplify the problem. In this way, strategies with optimal action potentials are addressed as initial steps in the intervention process. With success in these initial steps, a community may be better equipped to tackle the more difficult strategies, especially those that require institutional change, political will, and considerable investment of time and effort. The concept mapping method is a tool that communities may find useful as they try to identify practical ways to address complex public health issues.

\section{Conclusions}

Initial findings suggest that thematic clusters with high action potential usually represented ongoing activities within certain communities or actions communities could easily initiate. Community size, existing programs, partnerships, and policies, and influential advocates were among the cited factors affecting ease of implementation. Clusters with lower action potential require broader, longer term, policy, institutional or system-wide changes, and more resources. The high necessity clusters contained actions perceived as essential for change, but sometimes outside of a community's control. Participants identified a number of practical actions that were considered to hold potential for individual, community, and institutional changes which could result in decreasing racial disparities in infant mortality.

\section{Key Messages}

- Among the many social determinants of health that impact infant mortality, racism is one of the single, most important factors.

- The work of undoing racism and its associated impacts on infant mortality is an important, large-scale work that necessitates widespread policy changes and policy implementation, but must be initiated within and by communities. 
- Education is crucial to developing a foundational understanding of racial disparities in health and well-being.

- The need for education about racial disparities cuts across all educational, economic, social, and geographic sectors.

Acknowledgments Funding for the Infant Mortality and Racism Action Learning Collaborative was provided by the W.K. Kellogg Foundation. Many thanks to all of the members of the ALC Teams from Aurora, CO; Chicago, IL; Columbus, OH; Los Angeles County, CA; Milwaukee, WI; and Pinellas County, FL; Jessica Hawkins and Stacey Cunningham.

Disclaimer The findings and conclusions in this manuscript are those of the authors and do not necessarily represent the official position of the CDC.

\section{References}

1. Benjamins MR. Race/ethnic discrimination and preventive service utilization in a sample of Whites, Blacks, Mexicans, and Puerto Ricans. Med Care. 2012;50(10):870-6.

2. Borrell LN et al. Self-reported health, perceived racial discrimination, and skin color in African Americans in the CARDIA study. Soc Sci Med. 2006;63(6):1415-27.

3. Fujishiro K. Is perceived racial privilege associated with health? Findings from the Behavioral Risk Factor Surveillance System. Soc Sci Med. 2009;68(5):840-4.

4. Williams DR, Neighbors HW, Jackson JS. Racial/ethnic discrimination and health: findings from community studies. Am J Public Health. 2003;93(2):200-8.

5. Jones CP et al. Using "socially assigned race" to probe white advantages in health status. Ethn Dis. 2008;18(4):496-504.

6. Muennig P, Murphy M. Does racism affect health? Evidence from the United States and the United Kingdom. J Health Polit Policy Law. 2011;36(1):187-214.

7. Ryan AM, Gee GC, Laflamme DF. The association between selfreported discrimination, physical health and blood pressure: findings from African Americans, Black immigrants, and Latino immigrants in New Hampshire. J Health Care Poor Underserved. 2006;17(2): 116-32.

8. Hausmann LRM et al. Perceived discrimination in health care and use of preventive health services. J Gen Intern Med. 2008;23(10): 1679-84.

9. Hutson MA et al. Metropolitan fragmentation and health disparities: is there a link? Milbank Q. 2012;90(1):187-207.

10. Pickett KE et al. The effects of racial density and income incongruity on pregnancy outcomes. Soc Sci Med. 2005;60(10):2229-38.

11. Dominguez TP. Race, racism, and racial disparities in adverse birth outcomes. Clin Obstet Gynecol. 2008;51(2):360-70.

12. Fiscella K, Williams DR. Health disparities based on socioeconomic inequities: implications for urban health care. Acad Med. 2004;79(12):1139-47.

13. Hogue CJR, Bremner JD. Stress model for research into preterm delivery among black women. Am J Obstet Gynecol. 2005;192(5): S47-55.

14. Lu MC, Halfon N. Racial and ethnic disparities in birth outcomes: a life-course perspective. Matern Child Health J. 2003;7(1):13-30.

15. Rich-Edwards JW, Grizzard TA. Psychosocial stress and neuroendocrine mechanisms in preterm delivery. Am J Obstet Gynecol. 2005;192(5):S30-5.
16. MacDorman MF. Race and ethnic disparities in fetal mortality, preterm birth, and infant mortality in the United States: an overview. Semin Perinatol. 2011;35(4):200-8.

17. MacDorman MF, Mathews TJ. The challenge of infant mortality: have we reached a plateau? Public Health Rep. 2009;124(5):670-81.

18. Spong CY et al. Disparities in perinatal medicine: preterm birth, stillbirth, and infant mortality. Obstet Gynecol. 2011;117(4):948-55.

19. Collie-Akers V et al. Evaluating mobilization strategies with neighborhood and faith organizations to reduce risk for health disparities. Health Promot Pract. 2009;10(2 Suppl):118S-27S.

20. Israel BA et al. Community-based participatory research: lessons learned from the Centers for Children's Environmental Health and Disease Prevention Research. Environ Health Perspect. 2005;113(10):1463-71.

21. Minkler $\mathrm{M}$ et al. Promoting environmental justice through community-based participatory research: the role of community and partnership capacity. Health Educ Behav. 2008;35(1):119-37.

22. Minkler $M$ et al. Sowing the seeds for sustainable change: a community-based participatory research partnership for health promotion in Indiana, USA and its aftermath. Health Promot Int. 2006;21(4):293-300.

23. Wallerstein NB, Duran B. Using community-based participatory research to address health disparities. Health Promot Pract. 2006;7(3):312-23.

24. Minkler $\mathrm{M}$ et al. Ethical dilemmas in participatory action research: a case study from the disability community. Health Educ Behav. 2002;29(1):14-29.

25. Robinson JM, Trochim WM. An examination of community members', researchers' and health professionals' perceptions of barriers to minority participation in medical research: an application of concept mapping. Ethn Health. 2007;12(5):521-39.

26. MacDorman MF, Mathews TJ. Understanding racial and ethnic disparities in U.S. infant mortality rates. NCHS Data Brief. 2011;(74):1-8.

27. Mathews TJ, MacDorman MF. Infant mortality statistics from the 2007 period linked birth/infant death data set. Natl Vital Stat Rep. 2011;59(6):1-30.

28. Collins Jr JW et al. Very low birthweight in African American infants: the role of maternal exposure to interpersonal racial discrimination. Am J Public Health. 2004;94(12):2132-8.

29. Nuru-Jeter A et al. "It's the skin you're in": African-American women talk about their experiences of racism. an exploratory study to develop measures of racism for birth outcome studies. Matern Child Health J. 2009;13(1):29-39.

30. Rich-Edwards J et al. Maternal experiences of racism and violence as predictors of preterm birth: rationale and study design. Paediatr Perinat Epidemiol. 2001;15:124-35.

31. Rosenberg L et al. Perceptions of racial discrimination and the risk of preterm birth. Epidemiology. 2002;13(6):646-52.

32. Dehlendorf $\mathrm{C}$ et al. Disparities in family planning. Am J Obstet Gynecol. 2010;202(3):214-20.

33. Gross CP et al. Racial disparities in cancer therapy: did the gap narrow between 1992 and 2002? Cancer. 2008;112(4):900-8.

34. Pletcher MJ et al. Trends in opioid prescribing by race/ethnicity for patients seeking care in US emergency departments. JAMA. 2008;299(1):70-8.

35. Voelker R. Decades of work to reduce disparities in health care produce limited success. JAMA. 2008;299(12):1411-3.

36. Byrd DR et al. Infant mortality: explaining black/white disparities in Wisconsin. Matern Child Health J. 2007;11(4):319-26.

37. Burke JG et al. An introduction to concept mapping as a participatory public health research method. Qual Health Res. 2005;15(10):1392410 .

38. Trochim W, Cabrera, D. The complexity of concept mapping. Emergence: complexity and organization. 2005;7(1):11-22.

39. Kane M, Trochim WMK. Concept mapping for planning and evaluation. Thousand Oaks: Sage; 2007. 
40. Trochim WM et al. Practical challenges of systems thinking and modeling in public health. Am J Public Health. 2006;96(3):538-46.

41. Jackson K, Trochim W. Concept mapping as an alternative approach for the analysis of open-ended survey responses. Organ Res Methods. 2002;5(4):307-36.

42. Walker RE, Kawachi I. Use of concept mapping to explore the influence of food security on food buying practices. J Acad Nutr Diet. 2012;112(5):711-7.

43. Trochim WM et al. Setting objectives for community and systems change: an application of concept mapping for planning a statewide health improvement initiative. Health Promot Pract. 2004;5(1):8-19. discussion 10.

44. CityMatCH. Partnership to eliminate disparities in infant mortality. 2009; Available from: http://citymatch.org/projects/partnershipeliminate-disparities-infant-mortality-pedim. Accessed 24 Jan 2014

45. Abdul-Quader AS, Collins C. Identification of structural interventions for HIV/AIDS prevention: the concept mapping exercise. Public Health Rep. 2011;126(6):777-88.

46. Jabbar AM, Abelson J. Development of a framework for effective community engagement in Ontario, Canada. Health Policy. 2011;101(1):59-69.

47. Rosas SR, Kane M. Quality and rigor of the concept mapping methodology: a pooled study analysis. Eval Program Plan. 2012;35(2):236-45.

48. Trochim W, Kane M. Concept mapping: an introduction to structured conceptualization in health care. Int J Qual Health Care. 2005;17(3): 187-91.
49. Davison M. Multidimensional scaling. New York: Wiley; 1983.

50. Kruskal J, Wish M. Multidimensional scaling. Beverly Hills: Sage; 1978.

51. Everitt B. Cluster analysis. 2nd ed. New York: Halsted; 1980. a Division of John Wiley and Sons.

52. National Partnership for Action to End Health Disparities. 2013. U.S. Department of Health and Human Services. Available from: http:// minorityhealth.hhs.gov/npa/. Accessed 24 Jan 2014

53. Chao SM et al. Integrated approaches to improve birth outcomes: perinatal periods of risk, infant mortality review, and the Los Angeles Mommy and Baby Project. Matern Child Health J. 2010;14(6):82737.

54. Peck MG, Sappenfield WM, Skala J. Perinatal periods of risk: a community approach for using data to improve women and infants' health. Matern Child Health J. 2010;14(6):864-74.

55. Sappenfield WM et al. Perinatal periods of risk: analytic preparation and phase 1 analytic methods for investigating feto-infant mortality. Matern Child Health J. 2010;14(6):838-50.

56. Sappenfield WM et al. Perinatal periods of risk: phase 2 analytic methods for further investigating feto-infant mortality. Matern Child Health J. 2010;14(6):851-63.

57. Green AE, Aarons GA. A comparison of policy and direct practice stakeholder perceptions of factors affecting evidence-based practice implementation using concept mapping. Implement Sci. $2011 ; 6: 104$.

58. Jones CP. Levels of racism: a theoretic framework and a gardener's tale. Am J Public Health. 2000;90(8):1212-5. 